SILVA JÚNIOR, João dos Reis, Oliveira, João Francisco de e Mancebo, Deise (Orgs). Reforma universitária: dimensões e perspectivas. Campinas: Editora Alínea, 2006231 p. (Coleção políticas universitárias).

\section{Universidade no Brasil e na América Latina: tensões e contradições entre o público e o privado}

A publicação do livro Reforma universitária: dimensões e perspectivas é uma iniciativa editorial alvissareira. A um só tempo disponibiliza em uma bem cuidada edição a produção do Grupo de Trabalho Educação Superior da ANPEd, divulgando os 14 trabalhos apresentados na $29^{\mathrm{a}}$ Reunião Anual (2006), e inaugura a Coleção Ensino Superior que tem como objetivo socializar a produção do referido grupo de trabalho. A comissão editorial da nova coleção é constituída pelos organizadores da presente coletânea, coordenadores atuais e pretéritos do mesmo grupo, e o seu conselho editorial é composto por destacados estudiosos do tema. A criação desse espaço de debates é um importante acontecimento para o campo de estudos a respeito da educação superior. Em tempos de relativismo e de neopositivismo, a afirmação de uma linha editorial capaz de reunir a produção de conhecimento crítico e, em especial, a pesquisa que recusa a neutralidade ética diante dos graves problemas da educação brasileira, comporá a história da transformação democrática da universidade pública brasileira.

A quantidade - e a profundidade - de medidas que alteram a relação entre a universidade, o Estado e o mercado é um claro indicador de que as universidades brasileiras e latino- americanas entraram em um circuito dito reformador de proporções tectônicas.

Conforme informações

disponibilizadas na página $w e b$ do

INEP somente no Governo Lula da Silva foram editadas vinte e três Portarias, dois decretos e aprovadas duas leis, apenas para regulamentar a avaliação e o credenciamento das instituições de ensino superior!

Mesmo recusando a crença idealista de uma idéia de universidade, como presente de algum modo no pensamento de Schelling, Humboldt e Schleiermacher, fundadores da universidade autônoma alemã, ainda assim, é forçoso reconhecer que toda essa avalanche de atos normativos, de parcerias com as empresas, como as possibilitadas pelas parcerias público-privadas, está conformando uma instituição que pouco tem a ver com os conjuntos de idéias, conceitos e formas organizacionais que foram forjados na modernidade e que, afinal, permitiram a criação de universidades capazes de produzir conhecimento sumamente relevante em todos os domínios da vida humana.

Com efeito, a preocupação moderna de criar uma instituição capaz de assegurar a existência de um espaço público de produção de conhecimento em que a ciência pudesse ser institucionalizada livre das tutelas da religião e dos interesses particularistas de governos e do capital - projeto esse consolidado no conceito de universidade autônoma e com organização estatal - permitiu a consolidação de algumas das melhores universidades do mundo. Entretanto, se até o período que Hobsbawm denominou de trinta gloriosos anos do capitalismo, diversos Estados "toleraram" esse modelo pois, a despeito da relativa autonomia universitária frente ao governo e ao mercado, beneficiaram-se dos efeitos sociais de uma ciência institucionalizada e da formação profissional técnico-cientificamente referenciada, nas três últimas décadas esse quadro foi alterado em profundidade.
Nos países capitalistas dependentes esses processos heteronômicos foram particularmente destrutivos. Em "Financiamento da educação superior brasileira nos anos de neoliberalismo", Kátia Lima argumenta que o tributo neocolonial da dívida estrangula de modo dramático o Estado social e, como não poderia deixar de ser, a universidade pública. E, ainda mais grave, esse constrangimento financeiro não é conjuntural, compondo um novo desenho do Estado delineado por mudanças institucionais - como pela conversão da educação em serviço - que concretizam as orientações do Banco Mundial de diversificação das fontes de custeio das instituições públicas. A naturalização da prática em curso de que cabe ao Estado realimentar o moinho satânico da dívida, alocando grande parte da verba pública para o bolso dos portadores de títulos da dívida pública (57 mil privilegiados), tem levado não apenas o Ministério da Educação (MEC), mas também os sindicatos e a Confederação Nacional de Trabalhadores da Educação a apoiar a conversão de uma pequena fração da dívida em educação, uma tese que o Banco Mundial e a UNESCO vêm difundindo e que beneficiariam os países que "aplicam as políticas econômicas e educacionais adequadas". Lima conclui que o Governo Lula da Silva manteve os delineamentos mais gerais dos organismos internacionais (e por extensão, os do Governo Fernando Henrique Cardoso) para a educação superior e que, por isso, as lutas em defesa da educação superior pública devem compor uma agenda mais ampla, capaz de enfrentar a condição capitalista dependente do país.

A gênese das principais medidas do Governo Lula para a educação superior é examinada por Célia Otranto em "A reforma da educação superior do governo Lula: da inspiração à implantação". O estudo empírico sistemático das principais medidas para a edu- 
cação superior do atual governo leva a autora a sustentar que o documento fundador das medidas educacionais de todo o primeiro mandato é o polêmico relatório do Grupo de Trabalho Interministerial (GTI), divulgado informalmente em dezembro de 2003. Sua divulgação provocou uma série de estudos e comentários críticos, pois, o relatório indica como soluções alternativas problemáticas como a contração de bolsistas, a ampliação da carga horária docente e, principalmente, a adoção da modalidade de educação a distância para ampliação do acesso ao ensino superior prevendo a criação de 600 mil vagas. As hipóteses de financiamento elencadas no referido relatório previram a contribuição de alunos e ex-alunos (ou seja, o fim da gratuidade), a troca de parte da dívida por educação (alternativa discutida também por Kátia Lima) e o pagamento de imposto de renda diferenciado para ex-alunos. Este relatório causou enorme impacto, pois tornou evidente que o novo governo não iniciou o seu mandato a partir das proposições educacionais que compunham a agenda histórica do Partido dos Trabalhadores e de seus mais destacados educadores. Embora esse documento tenha sido renegado pela equipe de Tarso Genro, Otranto sugere que a agenda do atual governo tem nele os seus principais pilares.

Para os sindicatos, o movimento estudantil autônomo e as entidades acadêmicas que durante quase uma década criticaram a crescente adesão do país aos grandes delineamentos do Banco Mundial, em especial no longo período Fernando Henrique Cardoso, a realização do seminário "Universidade do Século XXI”, apoiado pelo Banco Mundial (e, portanto, reconhecendo a legitimidade desse organismo na definição do campo de políticas para a educação superior brasileira) e a terceirização do debate da reforma por meio de uma organização não-governamental francesa (Observatório de Reformas Universitárias - ORUS), dirigida por Edgar Morin, foram indicadores que acentuaram as preocupações sobre os termos do relatório do GTI. A materialização de medidas como o ProUni, a Lei de Inovação Tecnológica, as Parcerias Público Privadas (PPP), a regulamentação da educação profissional (Decreto $n$. 5.154/04), a educação a distância, a conexão entre avaliação e financiamento e a institucionalização das fundações ditas de apoio privadas, na interpretação de Otranto e Lima confirmaram a permanência da macroagenda hegemônica nos anos 1990 no alvorecer do novo século.

O problema da permanência ou não das condicionalidades dos organismos internacionais é um tema que ganhou relevância nos últimos anos, em especial pelo direcionamento de suas orientações para medidas capazes de aliviar a pobreza e de impulsionar uma nova geração de reformas, como as do sistema de seguridade e previdência, da legislação trabalhista e sindical e da educação básica e superior. O tema assume um caráter mais polêmico, tendo em vista que essas "reformas" compõem a pauta do Governo Lula que, igualmente, acolhe a tese do alívio à pobreza.

Em "Política para o ensino superior 1995-2006: ruptura e continuidade entre o público e o privado", Cristina H.A. de Carvalho desenvolve a hipótese de que a política pública direcionada ao ensino superior não é o resultado exclusivo da intervenção dos organismos internacionais. Introduz uma questão importante em termos teóricos e de método: está claro que a agenda dos documentos dos organismos internacionais (e poderíamos dizer: as proposições dos teóricos do neoliberalismo, como Hayek) nunca encontram correspondência estreita com a realidade das políticas efetivamente encaminhadas nos países. A rigor, é preciso indagar se políticas concretas implementadas por governos seguem roteiros estabelecidos por consultores e analistas de organismos internacionais de forma mecânica. Uma das brilhantes teóricas do Banco Mundial e, depois do Fundo Monetário Internacional, Anne Krueguer, ensinou aos governos latinoamericanos e de outras partes do mundo que a agenda dos organismos internacionais deve ter implementação gradual e deve ser negociada no seio do que Gramsci denominou de bloco histórico. Assim, não parece ser um bom método comparar as medidas previstas nos documentos do Banco Mundial com as que os governos implementam. Embora não fosse o objetivo da autora, poderia ser fecundo analisar a coalizão de classes que opera as políticas do Governo Lula e, a partir desse prisma, examinar a natureza das tensões entre as agendas desse governo e dos organismos internacionais para além da constatação de ambigüidades entre as mesmas.

Essa consideração teórica possivelmente contribuiria para avançar na análise da relação entre a política econômica e a educacional dos governos. Muitas vezes os estudiosos e dirigentes partidários e sindicais sublinham que o MEC é a favor da educação pública, inclusive conceitua a educação como "bem público", mas a área econômica cria obstáculos e dificuldades que acabam prejudicando a mesma educação pública. Retomando Florestan Fernandes, a pergunta mais importante é: os setores hegemônicos da coalizão de classes do Governo Lula têm interesse em romper com a heteronomia cultural que marca o sistema educacional? A partir de uma pergunta assim elaborada talvez fosse possível romper com a esquizofrenia da crença de que é possível um mesmo bloco histórico comportar governos múltiplos e em 
disputa. É certo que existem contradições, lutas, tensões, mas um bloco de poder em ascensão expressa uma hegemonia, por isso, os elementos regressivos das agendas de Cardoso e de Lula, assim como os pensados como positivos, devem ser considerados vis-à-vis ao bloco de poder e às lutas sociais.

Carvalho enfatiza corretamente que parte da agenda do Banco Mundial não se efetivou no Governo Fernando Henrique Cardoso, como a transformação das universidades em organizações sociais e o fim da gratuidade nos estabelecimentos oficiais. Sublinha corretamente que essas medidas desejadas por Cardoso não foram exitosas devido às resistências, principalmente, das grandes lutas magisteriais de $1998 \mathrm{e}$ 2001. Entretanto, examinando retrospectivamente, é forçoso reconhecer que embora a gratuidade não tenha sido extinta, a agenda do Banco Mundial, tal como teorizada pelo próprio organismo, indubitavelmente avançou. Como está expresso no famoso documento de $1994,{ }^{1}$ o fim da gratuidade é um processo que tem início com a diversificação das fontes de custeio das instituições públicas, orientação que vem se aprofundando desde então. $\mathrm{O}$ mesmo pode ser dito a respeito da conversão das universidades públicas em organizações sociais. O objetivo dessa medida era justamente viabilizar os contratos de gestão (forçando as universidades a fazer contratos com o Estado e com as empresas objetivando alcançar determinadas metas).

Atualmente, esse propósito pode ser alcançado pelas parcerias público-privadas como as expressas na Lei de Inovação Tecnológica proposta pelo Governo Lula.

${ }^{1}$ World Bank, La enseñanza superior: Las lecciones derivadas de la experiencia, Wash. D.C., World Bank, 1995.
Na maior parte dos artigos sobressai a problemática público-privado da qual emerge noções como educação como bem público, fórmula esta abraçada pelo atual governo. Em Carvalho, o conceito de bem público é apresentado como em desacordo com as recomendações do Banco Mundial e como um exemplo das contradições do governo; em Lima e, parcialmente, em Gomes, alternativamente, tal conceito possibilita maior indiferenciação entre o público e o privado. Gomes lembra que antes de público é preciso estar atento para a expressão "bem" e Lima sublinha que essa conceituação permite que a educação possa ser indistintamente ofertada por entes públicos e privados.

Ainda no terreno conceitual, Alfredo Gomes em seu estudo "Identidades discursivas público-estatal e privado-mercado: desafios teóricos ao campo da educação superior?" sustenta a necessidade de maior adensamento teórico e, mais precisamente, epistemológico, no debate público-privado.

Conforme o autor, "parte significativa dos trabalhos analítico-interpretativos as constrói como antinômicas, cuja coexistência é, sobretudo, de negação e oposição (...) e ao instituí-las como polares e antinômicas (...) pode-se criar obstáculos significativos ao potencial analítico-interpretativo do campo (...)" (p.157). A exemplo do debate sobre os "bens públicos", a natureza das mediações entre o público e o privado não pode ser considerada uma questão resolvida nem no plano teórico tampouco no terreno da prática política cotidiana ou na estratégia política.

Para que o debate a propósito das conexões entre o público e o privado avance seria importante partir da consideração de que existem perspectivas teóricas que se opõem à interpretação dessas mediações. Em seu estudo, Gomes chama a atenção para a necessidade de pensar o público e o privado não como categorias a priori, mas como categorias históricas. Na obra de muitos autores marxistas, como Raymond Williams, ${ }^{2}$ por exemplo, público e privado não são duas esferas antinômicas ou polares, como expresso na problematização de Gomes, mas sim contraditórias. Buscando o sentido histórico desses termos, Williams propõe que um dos sentidos possíveis para o privado vem de privare (privação, demarcando o que é privilégio e de poucos), enquanto a raiz de público vem de publicus ou poblicus (designando o que é de todos, o que pode ser universal). Na perspectiva marxista, a realização de um direito universal somente é possível com a negação dos privilégios e, por isso, as mediações entre o público e o privado correspondem aos termos das contradições que cindem a sociedade capitalista. É importante sublinhar que nos estudos marxistas o público não corresponde ao estatal, justamente porque o Estado em uma sociedade capitalista é, ele mesmo, particularista.

Em Giddens, ${ }^{3}$ distintamente, a oposição público-privado é obsoleta, pois o público, compreendido como o que atende ao interesse social, pode ser fornecido pelo Estado ou por entes privados. É essa compreensão que leva o ex-ministro Tarso Genro a destacar que como o Estado compra as vagas disponibilizadas pelo Programa Universidade para Todos (ProUni) estas são públicas, como se não houvesse diferenças substantivas entre uma instituição empresarial e uma instituição

${ }^{2}$ Raymond Williams, Palabras clave. Un vocabulario de la cultura y la sociedad, Buenos Aires, Nueva Visión, 2000.

${ }^{3}$ Anthony Giddens, Admirável mundo novo: o novo contexto da política, em D. Miliband (Org.), Reinventando a esquerda, São Paulo, UNESP, 1997. 
estatal referenciada nas normas do direito público e, ainda, como se o fato do Estado aportar recursos em algum ente privado o convertesse em fornecedor de ensino público.

É importante ressaltar que o Estado vem subsidiando com recursos públicos diretos ou indiretos o setor privado, de modo sistemático, desde a ditadura empresarial-militar. Cardoso foi generoso na concessão de benefícios para as instituições ditas filantrópicas e subsidiou o crescimento do setor empresarial (particular) com vultosos recursos do BNDES. Com o ProUni o Governo Lula avançou na transferência de recursos públicos para as instituições com fins lucrativos. Ademais, a ação do Estado em favor das fundações de apoio que proliferam nas universidades públicas opera no mesmo sentido da hipertrofia da esfera privada. Assim, as políticas concretas que estão em curso desde o governo empresarial-militar estão hipertrofiando a esfera privada, corroborando a análise de que o Estado capitalista é ele mesmo particularista. $\mathrm{O}$ público, como uma categoria relacional, encontra-se debilitado pela correlação de forças entre as classes fundamentais e o intento de diluição das fronteiras que o opõe ao privadomercantil é parte da ofensiva ideológica neoliberal.

Nessa redefinição conceitual do público e do privado, a avaliação tem uma importância axial nas políticas neoliberais. Em "Ponto e contraponto na avaliação institucional: análise dos documentos de implantação do SINAES”, José Carlos Rothen examina as políticas do Estado para a avaliação opondo duas perspectivas: a emancipatória, cujo exemplo mais relevante foi o Programa de Avaliação Institucional das Universidades Brasileiras (PAIUB), e a regulatória, exemplificada pelo "Provão" (como ficou conhecido o Exame Nacional de Cursos -
ENC). $\mathrm{O}$ autor faz um cuidadoso inventário da legislação e da normatização da avaliação no período Cardoso, indicando as resistências contra a consolidação de tais mecanismos avaliativos. Um dos exemplos da efetividade dessas lutas, mencionado pelo autor, foi a revisão da determinação de que o resultado do "Provão" deveria constar no histórico escolar do estudante. O mesmo esforço de examinar toda a trajetória da legislação e normatização pode ser encontrado no estudo da constituição do Sistema Nacional de Avaliação da Educação Superior (SINAES), em que, conforme o autor, oscilam perspectivas emancipatórias e regulatórias. Em muitos aspectos a Lei n. 10.861/04 e o Decreto-ponte de fevereiro de 2006 reforçam o braço do Estado avaliador, ao passo que determinadas normas da Comissão Nacional de Avaliação da Educação Superior (CONAES) aproximam-se da concepção do PAIUB, por enfatizar a autoavaliação. Considerando a detalhada análise das implicações do "Provão" para a conformação do "Estado avaliador", o estudo seria ainda mais enriquecido com uma análise mais sistemática do Exame Nacional de Desempenho dos Estudantes (ENADE), o sucedâneo do "Provão", e que, ao contrário deste, constará no histórico escolar do estudante, criando uma espécie de "selo de qualidade" muito apreciado pelo setor privado.

A leitura do trabalho de Stella Segenreich "Desafios da EAD ao sistema de educação superior: o triplo papel da avaliação" oferece um levantamento consistente do estado-da-arte da expansão da educação à distância (EAD). A autora sublinha as imensas dificuldades de obter informações precisas sobre os distintos cursos de graduação em andamento no país e, principalmente, nas disciplinas ditas semipresenciais, uma situação preocupante tendo em vista o crescimento extraordinário dos cursos de graduação no Governo Lula: em 2003 eram 15 cursos, sendo 13 deles públicos. Em março de 2006, o total de cursos saltou para 76, sendo apenas 37 públicos, o que atesta a pertinência da preocupação de que essa modalidade de curso poderia ser constituída em um novo filão de negócios para os empresários da educação. O trabalho é também um cuidadoso estudo sobre as formas de regulamentação dessa modalidade de ensino no país, permitindo novos estudos sobre seu significado, por exemplo, para a formação de professores, em especial pelo lugar conferido pelo MEC à "Universidade Aberta do Brasil". Embora não tenha sido objeto da investigação da autora, o avanço na conformação de um campo de negócios de educação mundial, novos estudos terão de examinar a expansão da pós-graduação a distância stricto sensu "profissional" sem a necessidade de dissertações e teses e com reconhecimento do diploma por instituições privadas que, inclusive, podem estar em associação com as empresas estrangeiras, conforme previsto no projeto do governo no Congresso Nacional (PL n. 7.200/06).

O conhecimento do processo de Bolonha, nesse sentido, é crucial para compreender o sentido da criação de um espaço europeu de educação superior que, na ótica dos que mercantilizam a educação, pode significar um robusto mercado educacional: essa é a expectativa da OCDE-

UNESCO que, inclusive, incentiva a difusão do comércio transfronteiriço de educação superior. O estudo de Mário Luiz Azevedo, "A integração dos sistemas de educação na Europa: de Roma a Bolonha ou da integração econômica à integração acadêmica" é oportuno, pois propugna que, para além das intenções republicanas e cidadãs, a harmonização dos sistemas não está desvinculada dos negócios e, tampouco, da reestruturação dos siste- 
mas de educação superior. O modelo preconizado pelo Relatório Attali de uma graduação genérica em três anos, tem suscitado intensos debates e mobilizações justamente por representar a possibilidade de um sistema mais abreviado e massificado em detrimento de um conceito de educação superior que, historicamente, foi construído em vários países europeus. É previsível, conforme o estudo de Azevedo, que esse sistema massificado seja uma das dimensões da integração, pois existe a possibilidade de uma integração que abarque apenas as instituições de maior prestígio e de tradição em pesquisa, conformando uma dualidade. Não é demais lembrar que, também no Brasil, esse modelo vem sendo apresentado como uma "alternativa genial" para ampliar o número de vagas para estudantes nas instituições públicas, sem alterar o padrão medíocre de financiamento da educação.

Transformações tão profundas e amplas não poderiam deixar de alcançar a natureza do trabalho docente em seu cotidiano. É, portanto, significativo e relevante que os trabalhos de Mari Forster e Maurício Fagundes, Denise Leda, Ana Maria Machado e Lucídio Bianchetti examinem questões referentes ao trabalho docente e à própria docência.

Em "Trabalho docente no ensino superior sob o contexto das relações sociais capitalistas", Denise Leda critica as teses do fim da centralidade do trabalho na formação do ser social, investigando o trabalho docente no contexto do capitalismo "flexível", em que a intensificação do trabalho caminha pari passu ao produtivismo estéril, ao consumismo acadêmico, à criação de rotas de excelência, em que ser um empreendedor é mais relevante do que praticar a docência. Situação que, no setor privado, é ainda mais alienante, o que corrobora a impostura da afirmação de que o privado hoje assume no- vas feições que o aproxima da esfera pública. A questão de fundo, conforme a análise da autora, é que muitas dessas disposições ideológicas estão arraigadas na subjetividade dos professores, repercutindo no conceito de pesquisa, de produção de conhecimento, de conhecimento novo, em suma, na concepção de docência.

A partir de um outro prisma, a questão da docência é abordada por Ana Maria Machado e Lucídio Bianchetti que discutem um tema crucial, mas pouco debatido na academia. Em "Orientações de teses e dissertações: individual e/ou coletiva? Contextos e transformações nos 40 anos da pós-graduação stricto sensu no Brasil", os autores analisam as condições de produção dos trabalhos acadêmicos em três grandes períodos ou gerações: no período em que a pós-graduação era incipiente e pouco institucionalizada (até os anos 1990), no período de expansão, no contexto da chamada redemocratização e, finalmente, a partir do modelo CAPES de avaliação do período 1996-1998. O trabalho é desenvolvido a partir de um levantamento empírico amplo que permite os autores evidenciar nexos sutis entre as políticas para a educação superior e os critérios de avaliação da CAPES. Entre dados coletados com entrevistados, são recorrentes as constatações de que atualmente o sistema de fomento espera que a pós-graduação esteja dirigida explicitamente para a formação do pesquisador ou, ainda mais precisamente, de um determinado perfil de pesquisador, em tempo curto e com elevado perfil de "produtividade". Contudo, esse modelo nem sempre é capaz de assegurar condições de formação de pesquisadores que contemple o conhecimento das referências clássicas, a discussão do método (e não apenas de técnicas de pesquisa) e o processo coletivo de construir rigorosamente um objeto de pesquisa, articulando esses saberes a uma reflexão sobre as mediações singulares que configuram a instituição universitária e a docência.

A mesma preocupação com a formação - aqui não do mestrando ou do doutorando - mas dos professores universitários, pode ser vista em "Dormi aluno(a)... acordei professor(a): interfaces da formação para o exercício do ensino superior”. Ana Maria Cunha, Talamira Brito e Graça Cicillini investigam a passagem da condição de pósgraduando para a de professor, enfatizando, justamente, a ausência de espaços de aprendizagem da docência. Como expressão do maior pragmatismo da formação na pós-graduação stricto sensu, salientado por Machado e Bianchetti, os futuros docentes ingressam no magistério superior sem uma reflexão mais sistemática sobre a universidade, o currículo, a avaliação e o processo ensino-aprendizagem, situação que possivelmente explica, ao menos em parte, as enormes dificuldades de aprendizagem dos estudantes das áreas tecnológicas e das ciências da natureza.

\section{Mari Forster e Maurício}

Fagundes, em "Inovações educativas na sala de aula universitária: ruptura paradigmática/resistência ao ethos regulatório", salientam o peso do pensamento único no fazer universitário, colocando em relevo a padronização das formas de conhecimento e a cegueira epistemológica dos processos educacionais subordinados à ideologia da globalização, que se traduzem em práticas de avaliação em que as inovações são vistas como ruídos - como, por exemplo, ocorreu no "Provão" e poderíamos ampliar para o ENADE. Com isso, é comum encontrar professores que confundem as inovações pedagógicas com o uso das tecnologias da informação e comunicação. As formas inovadoras de aprendizagem ensejadas pelos diálogos com os movi- 
mentos sociais que recuperam elementos da pedagogia em que os coletivos de estudos são auto-organizados, em que cada estudante tem que ser um protagonista da produção e socialização do conhecimento, em suma, de práticas pedagógicas congruentes com uma nova episteme, são submetidas a intenso constrangimento em decorrência do padrão de avaliação dito científico que se alastrou em toda a América Latina como se esta avaliação fosse de fato alta ciência.

O livro contempla um estudo de tema crucial para a democratização da educação superior: em "Mitos e controvérsias sobre a política de cotas para negros na educação superior", Mariluce Bittar e Carina Almeida, a partir da experiência da Universidade do Estado de Mato Grosso do Sul, debatem a temática por meio de um breve histórico das lutas pelos direitos civis dos negros e da reunião de indicadores relevantes sobre o racismo existente contra os negros e, sobretudo, aqueles provenientes das classes populares. Um histórico breve envolve inevitavelmente limitações, como a afirmação de que as lutas contra a discriminação se originaram na Revolução Americana (1776) e na Revolução Francesa (1789), para, a partir daí, examinar as conferências da ONU contra a discriminação. Este viés de análise não coloca em relevo a problematização da própria classificação dos seres humanos em "raças" pelo colonialismo eurocêntrico (que fez com que as classes na América tivessem cor), os processos de formação dos Estados-nação que não incluíram de fato a maioria dos povos e as lutas contra o padrão eurocêntrico de poder e de saber protagonizada pelos povos originários (como por Tupac Amaru) e pelos jacobinos do Haiti. Essa leitura da história leva as autoras a colocar as cotas como o desdobramento das lutas antiracistas, em detrimento das lutas que propugnaram sociedades radicalmente não-racistas e livres de exploração, valorizando a cultura e a etnia como no processo de descolonização da África e mesmo em muitos movimentos que lutaram nos Estados Unidos da América pelos direitos civis. A adoção da perspectiva de que o ápice das lutas contra a discriminação tem como ponto culminante a cota leva as autoras a negligenciar a existência de distintos pontos de vista no seio do movimento negro sobre a questão, não apenas a respeito da pertinência das cotas, mas sobretudo sobre como compreender e implementar as cotas. Questões de fundo, ainda insatisfatoriamente resolvidas no debate acadêmico-político, como o problema da classificação "racial", não são abordadas, levando as autoras a adotar uma classificação oscilante, conforme o ponto de vista a ser defendido, ora negros e pardos são apresentados como distintos, ora ambos aparecem agrupados na categoria "negros". Outro ponto complexo que merece maior discussão é o pressuposto de que comissões de especialistas devem examinar o fenótipo para atribuir a cor ou a "raça" no momento da inscrição do candidato.

Considerando todo o debate a respeito da força relativa das condicionalidades dos organismos internacionais para a definição da política de ensino superior latino-americana, é positivo que entre os trabalhos publicados dois discutam, sob diferentes ângulos, a América Latina: um deles estabelece similaridades e diferenças entre Argentina, Brasil, Chile e México e o outro se detém no caso argentino.

A interconexão entre a economia brasileira e a argentina tornou-se evidente nas últimas décadas. Uma crise neste último país rapidamente chegava aqui, levando a imprensa a utilizar a expressão "efeito tango". As trajetórias históricas das universidades desses dois países são radicalmente distintas. Lamentavelmente, os acontecimentos de
Córdoba (1918) não se repetiram no Brasil. Entretanto, a partir da Crise da Dívida de 1982, medidas semelhantes foram aplicadas nos dois países, por isso, conhecer a realidade argentina é imprescindível. O bem documentado estudo de Mônica Mestman e Cláudio Suasnabar, "Autolimitación e intervencionismo estatal: las políticas universitárias en Argentina en viente años de democracia", fornece ao leitor uma síntese bem sistemática de três períodos: Alfonsín e a transição democrática (1983-1989), o período de maior intervenção estatal e de reconfiguração da educação superior, correspondendo ao governo Menem (1989-2000) e, finalmente, o período da crise de 2001 até o governo Kirschner (2000-2006). A exemplo das políticas empreendidas no Brasil, também na Argentina as fronteiras público-privadas foram deslocadas. Os autores preconizam que as medidas em curso tornaram a fronteira que medeia a academia e o Estado mais porosa. Após a ditadura, Alfonsín restabeleceu parcialmente a autonomia universitária, mas não logrou uma reconstrução efetiva, pois o seu governo foi tragado pela crise econômica. Menem implementou uma agenda de modernização a ferro e fogo, referenciando-se nas proposições do Banco Mundial, deslegitimando a universidade pública e colocando a avaliação no centro da agenda. Kirschner herdou um quadro muito difícil, provocado pela grave crise de 2001. Algumas de suas medidas podem provocar mudanças significativas na educação pública do país, como a nova lei de financiamento da educação superior que promete elevar os gastos com a educação para $6 \%$ do PIB. Entretanto, conforme os autores, a sua pauta ainda é incipiente e incapaz de alterar substantivamente $o$ quadro da educação superior, em especial as dívidas históricas do Estado com as universidades, a situação dos docentes sem remuneração, levando os auto- 
res a constatar que seu governo não logrou romper com a agenda anterior.

Armando Alcántara e Mônica da Rocha Silva, em "Semejanzas y diferencias en las políticas de educación superior en América Latina: cambios recientes en Argentina, Brasil, Chile y México", objetivam fazer um estudo não exaustivo sobre o curso das chamadas reformas educacionais nos países citados, buscando similaridades e diferenças entre as experiências de "reformas". Os autores sustentam que a crise econômica dos anos 1980 e o ajuste econômico para estabilizar as economias provocaram como desdobramento uma profunda redefinição do papel do Estado na educação que produziu efeitos que os autores qualificam como "indesejáveis". Aqui, a exemplo do que foi assinalado anteriormente, é preciso discutir se os efeitos são de fato indesejáveis ou se, a rigor, a coalizão de classes que se afirma como dominante após a crise da dívida não tem na universidade pública, gratuita e capaz de produzir conhecimento novo uma instituição estratégica para o seu projeto de poder. A análise empreendida sobre o lugar dos Estados na chamada globalização e a reduzida consideração das frações de classes que estão à frente dos blocos de poder, levam os autores a sugerir a existência de um modelo de globalização que dificilmente expressa o lugar da América Latina na economia-mundo, concretamente longe de uma economia em conexão com as fronteiras do conhecimento que se vale da ciência e tecnologia como diferencial para ocupar os nichos de mercado mundial. Os estudos sobre a economia latino-americana têm sugerido o contrário: a região hoje caminha a passos largos para a reprimarização.

Ao analisar os casos específicos, esse último estudo negligencia elementos importantes. Quando examinam as reformas na Argentina os autores sustentam que a aprovação da nova lei da educação superior na Argentina de Menem, em 1995 (Lei n. 24.251/95), se deu de modo negociado e consensual. O estudo de Mestman e Suasnabar publicado no presente livro se refere ao período de Menem como o de "implementação brutal" de "reformas", opinião corroborada por Mollis. ${ }^{4}$ Os autores indicam que a sistemática

${ }^{4}$ Ver Marcela Mollis, La niversidad argentina en tránsito. Ensayo para jóvenes y no tan jóvenes, Buenos Aires, Fondo de Cultura Económica, 2001. de avaliação em curso no Brasil, introduzida pela Lei n. 10.861/04, não é obrigatória, quando o caráter compulsório está claramente expresso na legislação. Entretanto, embora com imprecisões pontuais, o referido estudo assinala que, a despeito das particularidades históricas, não secundárias, está em curso uma agenda com fortes similaridades.

Em suma, a leitura deste livro instiga o investigador a se indagar a respeito das convergências das medidas de reforma em curso na América Latina, embora com importantes nuanças. Por que ocorre essa confluência? O que significa essa reconfiguração para os povos e as nações da região? O debate sobre o capitalismo dependente e a heteronomia cultural pode ganhar novo vigor a partir dessas perguntas que, atualmente, não são retóricas, em especial pela luta dos povos contra o padrão de acumulação imposto pelo ajuste dos anos 1980 .

\section{Roberto Leher}

Professor da Faculdade de Educação da

Universidade Federal do Rio de Janeiro

Coordenador do Grupo de Trabalho Universidade e Sociedade do Conselho Latino Americano de Ciências Sociais (CLACSO). 